\section{A POESIA DIDÁTICA ELEGÍACA E A POESIA ELEGÍACA DIDÁTICA DOS MEDICAMINA DE OVÍDIO, E OVÍDIO, PRODUTOS PARA A BELEZA FEMININA: TRADUÇÃO POÉTICA}

\section{Marcelo Vieira Fernandes*}

\section{A Poesia Didática Elegíaca e a Poesia Elegíaca Didática DOS MEDICAMINA DE Ovídio ${ }^{1}$}

Aptari magnis inferiora licet ("É lícito adaptar-se ao grande o que lhe é inferior"), diz o amante, em tom axiomático, numa elegia dos Amores de Ovídio (2.17.14), à mulher que, orgulhosa de sua beleza, poderia desprezá-lo em razão de ele não lhe estar à altura nesse quesito. É bem verdade que, aí, a argumentação do amante tem uma finalidade interna à ficção amorosa: os exemplos de Calipso e Odisseu (15-6), de Tétis e Peleu (17-8), de Vênus e Vulcano (19-20) tencionam autorizar a união de pares em princípio díspares. Mas, como é comum esperar em Ovídio, outro argumento vem a seguir que aponta para fora da ficção e, aproveitando-se do mesmo conceito de "adaptação" (cf. 14: aptari), se vale do próprio poema: Carminis hoc ipsum genus inpar, sed tamen apte / iungitur herous cum breuiore modo ("Este gênero mesmo de poema é desigual [i.e. formado de partes desiguais], mas, ainda assim, perfeitamente [apte] / se junta o [verso] heroico ao verso mais breve", 21-2).

O gênero de poema a que se refere Ovídio não é outro senão a elegia, que, a julgarmos pelo que o poeta diz num passo dos Remedia Amoris, não deve, quanto à matéria, cantar o que é próprio do metro meônio (cf. Rem. 373-4), nem o que cabe à tragédia (cf. 375), à comédia (cf. 376) ou ao iambo (cf. 377-8), mas há de cantar os "amores portadores de aljava" (cf. 379: pharetratos Amores), a "amiga" (ou "amante") "ligeira", "inconstante", que "brinca segundo a sua vontade" (cf. 380: et leuis arbitrio ludat amica suo) (ou, ainda, segundo um verso das Heroides, o lamento, que, ademais, lhe é próprio: cf. 15.7: elegiae flebile carmen). Esse passo, porém, dos Remedia - para não falar, aqui, de seu caráter digressivo, dado o restante do poema - talvez mereça um modo de leitura diferente do totalmente sério, já porque é Ovídio mes-
* Professor Doutor de Língua e Literatura Latina na FFLCH - USP.

1. O presente trabalho é versão adaptada de monografia apresentada como conclusão da disciplina de Pós-

Graduação "'Lírica' latina e seus gêneros confins: elegia, iambo e lírica", oferecida em 2004 na FFLCH - USP pelo Prof. Dr. João Angelo Oliva Neto (USP), a quem publicamente agradeço pela imensa qualidade do curso que nos ministrou, a nós alunos, e pela leitura cuidadosa que fez de minha monografia e de minha tradução. Agradeço, ainda, aos pareceristas anônimos da Classica, pelos reparos e sugestôes que fizeram, assim enriquecendo este trabalho. 
2. Cf., p. ex., Fast. 2.125-6: Quid uolui demens elegis imponere tantum / ponderis? heroi res erat ista pedis ("Por que fui querer, demente, à elegia impor tamanho / peso? Do pé heroico era esta matéria”); e Ib. 45-6: Prima quidem coepto commitam proelia uersu, I non soleant quamuis hoc pede bella geri ("Os combates, é verdade, travarei usando o verso já começado, / conquanto não seja costume neste pé fazer a guerra").

3. Cf. Conte, Gian Biagio, Genres and Readers: Lucretius, Love Elegy, Pliny's Encyclopedia, trans. Glenn W. Most with a foreword by Charles Segal. Baltimore:

Johns Hopkins University Press, 1994, p. 44: "Os Remedia são na verdade a destinação da obra de Ovídio em 'interpretar' e revisar o código da elegia, o que começou com os Amores e estava destinado a ser depositado numa construção literária nova

— um poema didático em dísticos - mais adequada aos deslocamentos sofridos pela retórica da elegia" (tradução minha, como nos demais autores modernos citados a seguir).

4. Não seria difícil, p. ex., apontar na Ars um sistema metafórico de recorrências à cinegética $\mathrm{e}$ à haliêutica; tão numerosas são as alusōes, aliás, que já se chegou a formular a hipótese de que Ovídio a tivesse escrito, ao menos em parte, como uma paródia à Cynegetica de Grácio Falisco, contemporâneo seu (cf.

Pont. 4.16.34): cf. ToOHey, Peter, Epic Lessons. An introduction mo quem reconhece algumas de suas próprias "inadequações” ou experimentos $^{2}$, já porque - especialmente quanto ao particular da matéria da elegia — se trata, nesse poema, duma revisão irônica do código elegíaco, com vistas a desmontá-lo, como aponta G. B. Conte ${ }^{3}$, já porque, enfim, os Remedia, a exemplo da Ars Amatoria, também podem ser lidos — o que obviamente inclui o trecho em questão - como uma paródia de outros discursos didáticos ${ }^{4}$. Pois curioso é que Ovídio - aí, em meio a um poema que trata de remédios para curar a enfermidade do amor — nos dê, como verdadeiro preceptor, uma aula sobre a relação entre as diferentes matérias poéticas e os respectivos metros seguindo um modo de apresentação em muito parecido àquele de Horácio nos versos 73-85 de sua Arte Poética ${ }^{5}$, nos quais, por sua vez, já se poderia entrever certo ar professoral, entre sério e cômico ${ }^{6}$, de modo a ficar comprometido, ou ao menos relativizado - dada a sequência, mais séria e detalhada, na epístola, acerca dos parâmetros do tom, do tipo das personagens, etc. — o caráter peremptório da relação aí apontada entre matérias poéticas, dum lado, e metros, do outro. O início dessa passagem dos Remedia, assim, talvez pudesse ser lido também de acordo com outro tom: o de quem interpela, intempestivamente, a sabedoria dos que conhecem tãosó teoricamente as distinçóes entre os gêneros poéticos, leitores lesados, talvez, pela excessiva liberdade da musa do poeta: At tu, quicumque es, quem nostra licentia laedit, I si sapis, ad numeros exige quidque suos ("Mas tu, quem quer que sejas, a quem nossa liberdade fere, / se tens discernimento [ou "se és conhecedor", "se aprendeste a lição"], reduze cada coisa [gênero] ao seu ritmo próprio", Rem. 371-2). Mais tarde, no segundo livro dos Tristia, resumirá a épica homérica (cf. 375-6; 377-80) e a vergiliana (cf. 533-6) dum modo que contraria, ao que parece, um trecho de sua aula de poética, pois nos Remedia pergunta retoricamente: Deliciis illic quis locus esse potest? ("Às delícias [i.e. "aos prazeres do amor"] que lugar pode aí [sc. no metro de Homero] haver?", 374), perguntando, depois, também retoricamente - admitindo, nesse ponto, a possibilidade duma leitura corrompida (como a que argumenta ter havido no caso de sua Ars) —, nos Tristia: Ilias ipsa quid est aliud nisi adultera de qua / inter amatorem pugna uirumque fuit? ("A Ilíada mesma o que mais é senão uma adúltera pela qual / entre o amante e o marido houve uma disputa?", 371-2; cf. ainda: 375-6; 377-80; 533-6; Am. 2.18.35-40): o que não tinha sequer uma parte, um lugar, no discurso épico, chega mesmo a definir-lhe a essência. O que parece certo dizer é que, 
se Ovídio de fato endossa tal discriminação ${ }^{7}$, tal como a apresenta nos Remedia, não o faz ao ponto de excluir, como poeta, as experimentações no espaço entre os gêneros de poesia, exercício da licença de sua musa, nem ao ponto de dispensar a relativa participação do leitor na própria definição do horizonte de significação do texto ${ }^{8}$.

Assim, já quando disse que o verso heroico ajusta-se bem (apte) ao verso breve ( $A m$. 2.17.21-2), estava, é verdade, apenas descrevendo o dístico elegíaco, como faz, aliás, noutros momentos (cf. ib. 1.1.3-4; 2.1.4; 3.1.8); extensivamente, porém, talvez se possa entrever, nessas formulaçōes, o germe da solução para aquele que, em Ovídio, parece ser um problema permanente: como um poeta afeito ao tema do amor, um poeta cuja musa é "jocosa" (cf. Tr. 2.313-4), poderia cantar os grandes temas da poesia mais elevada?? A solução poderia, talvez, consistir num futuro ajuste, de proporções ainda maiores: o da forma do discurso épico ("heroico", e por isso maior) à matéria erótica (elegíaca, e por isso menor), compreendidas, nesta última, as suas diferentes faces; e, a partir daí, por inversão, o ajuste dessa matéria erótica a certos imperativos do discurso épico ${ }^{10}$. Ora, se é verdade que da categoria do épos os antigos entendiam derivar-se a categoria, ou subespécie, da poesia didática ${ }^{11}$, então é possível admitir que, ao menos no interior duma certa tradição ${ }^{12}$ - aquela de Lucrécio, com o De Rerum Natura, e de Vergílio, com as Geórgicas -, a elevação e grandeza (material, inclusive) características da épica se estendessem também à sua modalidade didática ${ }^{13}$. A chamada "épica didática", então, infundida assim duma dignidade comparável à da épica "propriamente" dita, bem quadraria ao universo da poesia augustana, como já provara Vergílio, e como Ovídio mesmo, em seus Fastos, haveria de reconhecer ${ }^{14}$. $\mathrm{O}$ caso é que, no ciclo didático deste último formado pela Ars Amatoria, os Remedia Amoris e os Medicamina Faciei Femineae, a recuperação do modelo didático de Lucrécio e Vergílio não se dá unicamente pelo ajuste da retórica elegíaca ao discurso épico-didático "oficial", mas ainda por meio duma transposição deste último mediante a paródia ${ }^{15}$. Aproveitando-se da força desse discurso, Ovídio nele expóe uma matéria que, até então, só comparecera no registro baixo da elegia amorosa. Para tanto, empresta desse modelo não a forma métrica do hexâmetro - pois que, neste particular, mantém o dístico, já empregado antes nos Amores — mas a formulação to ancient didactic poetry. London and New York: Routledge, 1996, p. 199; e LEACH, Eleanor Winsor, "Georgic Imagery in the Ars Amatoria". Transactions and Proceedings of the American Philological Association, Vol. 95, 142-54, 1964, p. 142: "Embora Roma esteja sempre no primeiro plano do poema [sc. Ars Amatoria], as figuras de linguagem acrescentam uma dimensão geórgica. Um estudo detido de tais figuras mostra que as 'iscas no anzol' e as 'armadilhas estendidas' do poeta não são metáforas meramente incidentais, mas são parte dum consistente encadeamento linguístico que se estende por toda a obra”; p. 149: "O estilo da Ars Amatoria é também uma imitação cômica do das Geórgicas"; cf., ainda: p. $151 ; 154$.

5. Não quanto ao modo de apresentação, mas quanto aos termos, cf. AP 73: tristia bella: Rem. 373: fortia bella; AP 74: quo scribi possent numero mostrauit Homerus : Rem.373: Maeonio gaudent pede referri; AP 77: exiguos elegos: Rem. 379: blanda elegia; AP 79: proprio iambo : Rem. 377: liber iambus; AP 80: socci: Rem. 376: soccus; AP 80: grandes cothurni :

Rem. 375: tragicos cothurnos.

6. Cf., a esse respeito, ToOHeY, p. 153-4.

7. Pois, em que pese seu caráter estrito, ela ainda lhe serve para justificar, aos olhos de censura dos leitores antigos conhecedores de poética, a matéria de sua "musa proterva” (cf. Rem. 362): Quis feret Andromaches peragentem Thaida partes? 
I Peccat, in Andromache Thaida quisquis agat. I Thais in arte mea est; lasciuia libera nostra est; / nil mihi cum uitta; Thais in arte mea est ("Quem suportará Taís desempenhando o papel de Andrômaca? / Erra, quem em Andrômaca apresenta

Taís. / É Taís que aparece em minha Arte; a nossa brincadeira é livre; / nada tenho com a fita de cabelo

[i. e. com as matronas], é

Taís que aparece em minha Arte", 383-6).

8. Cf., a esse respeito, Gibson, Bruce, "Ovid on Reading: Reading Ovid. Reception in Ovid Tristia II". The Journal of Roman

Studies, Vol. 89, 19-37,

1999. Com base no exame da argumentação de

Ovídio no segundo livro

dos Tristia (2.263ss) segundo a qual toda espécie de poesia é potencialmente danosa, a depender da leitura que se faz -

Gibson, além de explicar certas incongruências de tal argumentação, entende que Ovídio delega, ou transfere, ao leitor grande parte da responsabilidade na construção do significado do poema, inclusive

daquele mesmo que então está sendo lido, ou seja, esse livro mesmo dos

Tristia. Se isso, de resto, pode parecer um truísmo, não há de ser ignorado, contudo, nalgumas de suas implicaçōes para a maneira de ler a poesia didática de Ovídio (cf. infra).

9. Assim, bem quando se preparava para cantar "as armas e violentas guerras" (cf. Am. 1.1.1-2), Cupido riu e, do metro, que era para ser o hexâmetro, subtraiu-lhe um pé, didática do conjunto, vale dizer: a manutenção duma relação entre mestre e discípulo (mediante asserções de competência, apóstrofes, etc.), a organização cuidadosa do material da instrução (por meio da articulação do discurso em livros ou seçôes menores, pontuadas por movimentos de recapitulação), o contraste dos exemplos e digressóes, a legitimidade do discurso baseada na ideia de utilidade da instrução, as máximas e provérbios, etc. ${ }^{16}$ Curioso é que, quando decide fazer poesia didática que trata de matéria elevada, nos Fastos, reclame da inadequação do metro: a combinação da matéria elevada dos Fastos com a formulação elevada do discurso didático - que tem seu pedigree, como foi dito, na épica - constitui peso demasiado grande para a pequenez do dístico (cf. Fast. 2.1256: Quid uolui demens elegis imponere tantum / ponderis? heroi res erat ista pedis, "Por que fui querer, demente, à elegia impor tamanho / peso? Do pé heroico era esta matéria"); porém a combinação da matéria amorosa com a formulação elevada do discurso didático, naquele ciclo de poemas, aceita, sem grande custo, a importação do dístico elegíaco, já que, por um lado, o tema desses poemas ainda faz parte do universo erótico e, por outro, a presença do dístico, aí, parece contribuir para a paródia, e não a simples imitação, daqueles modelos didáticos.

Aquela reclamação, assim, parece resultar inócua, para não dizer insincera, diante da evidência simples e maior que é o fato de o dístico ter sido empregado, a exemplo do que ocorreu naquelas três peças - nas quais esse metro tinha, por assim dizer, uma ambientação natural —, em toda a extensão dos Fastos, em que a matéria era para ser do "pé heroico"17. E não foi empregado, ao que parece, senão porque todos esses poemas representam, por um lado, uma leitura, pela ótica da elegia, da tradição épico-didática (e nesse ponto, especialmente, é que está a paródia), e, por outro lado, uma leitura, pela ótica da contemporaneidade de Ovídio, da tradição recente da própria elegia entre os romanos ${ }^{18}$. Ora, sobretudo no ciclo da sua poesia didática erótica, Ovídio parece deixar ao leitor um problema à primeira vista insolúvel: o que ele faz é uma acomodação do pequeno no interior do grande ou a interpretação do grande mediante o código do pequeno ${ }^{19}$ A resposta é talvez: as duas coisas. Pois acomodar o discurso elegíaco que, a partir daí e por isso mesmo, não se confunde mais com a simples elegia amorosa (do seruitium amoris) - no discurso mais amplo e elevado da poesia augustana equivale a uma ten- 
tativa de desconstrução desse mesmo reduzido discurso elegíaco, com vistas, não a extingui-lo de todo, mas a melhorá-lo, ampliando-o, tornando-o compreensivo e útil; por outro lado, o discurso elegíaco, na pequenez do dístico, serve como meio de relativizar a própria elevação do discurso oficial heroico, como uma declaração de intenções estéticas e políticas: a afirmação de que a poesia pode transformar-se e, num mundo cioso de recuperar antigos valores, a defesa da contemporaneidade.

Essa defesa comparece, de modo especial, naquele que de longe é o poema mais técnico do ciclo didático de Ovídio: os Medicamina Faciei Femineae (ou os "Produtos para a Beleza Feminina"). O poeta a eles se refere num passo da Ars em que recomenda às mulheres - seu público, no terceiro livro $^{20}$ — o cuidado com a beleza: Est mihi, quo dixi uestrae medicamina formae, I paruus, sed cura grande, libellus, opus: I hinc quoque praesidium laesae petitote figurae. I Non est pro uestris ars mea rebus iners ("Tenho um opúsculo em que disse os produtos para a vossa beleza, / pequeno, mas obra grande no cuidado: / nele também podereis buscar o socorro para os defeitos da aparência. / Naquilo que vos aproveita, não é sem arte a minha arte", 3.205-8). A beleza do corpo, no código elegíaco da Ars, é uma das estratégias para o sucesso no amor (cf. 3.101-2); os produtos, por sua vez, que a realçam e conservam (cf. Med. 1-2) — e que definem a "arte" desse opúsculo como a cosmética propriamente — são uma expressão bem sugestiva, como que metonímica, da refinada urbanidade do mundo romano (sobretudo à época de Ovídio), compreendidas nessa urbanidade a elegância do corpo e a cultura do espírito; são, numa palavra, uma das expressões do cultus ("cultivo", "cuidado" ou "trato"). A defesa desse "cultivo" — do "ornamento", em geral, e do "cosmético", em particular $^{21}$ —, presente nos Medicamina (cf. 1-10), aparece também, para não falar já dos Amores $^{22}$, num passo da Ars (cf. $\left.3.121-8^{23}\right)$ no qual funciona como argumento de causa para o elogio dos tempos contemporâneos, preferíveis à rusticidade (ou ao "desleixo": cf. 128: rusticitas) de tempos antigos ${ }^{24}$.

Os cosméticos são, pois, uma das faces da poesia erótica em Ovídio. O que acontece é que, além de também recomendá-los, como faz na Ars, o poeta os descreve detalhadamente, nos Medicamina, ensinando ao leitor o modo de produzi-los. A consequência disso é que, nesse último poema, também em dísticos elegíacos, a matéria é ostensivamente técnica ${ }^{25}$, o que deixando-o dístico elegíaco; ou quando se pôs a escrever tragédia, o Amor riu "de seu manto e de seus coturnos pintados" (2.18.15-6); cf. 3.1. Argumentará, depois: Tenuis mihi campus aratur; I illud erat magnae fertilitatis opus. I Non ideo debet pelago se credere, si qua I audet in exiguo ludere cumba lacu ("Humilde é o campo que aro; / aquela [sc. os temas épicos] era obra de grande fertilidade. / Não deve ao pélago uma barca confiar-se / só porque ousa brincar em pequeno lago", Tr. 2.327-30).

10. Já nos Amores, Ovídio acena para uma combinação em princípio desautorizada em seus Remedia: Nec tibi, qua tutum uati, Macer, arma canenti / aureus in medio Marte tacetur Amor I et Paris est illic et adultera, nobile crimen, I et comes extincto Laodamia uiro. I Si bene te noui, non bella libentius istis / dicis et a uestris in mea castra uenis ("Nem tu, Macro [= poeta que escreveu sobre a Guerra de Troia; cf. Pont. 2.10.2], lá onde é seguro [ou "tanto quanto é seguro"; cf.: qua tutum] a um poeta que canta as armas, deixas em silêncio, [mesmo] em meio aos combates, o dourado Amor, / e Páris lá [sc. em teus versos] está mais a adúltera, famoso crime, / e Laodamia, a acompanhar na morte o marido. / Se bem te conheço, tratas esses temas com não menor prazer [com] que [tratas] as guerras / e de teu campo vens para o meu”, 2.18.35-40). 
11. Como lembra L.E. Rossi, em "I generi letterari e le loro leggi scritte e non scritte nelle letterature classiche". Bulletin of the Institute of Classical Studies, 18, p. 69-94, 1971, p. 82: "É mister não dar dignidade de gênero independente àquilo que os antigos entendiam apenas somo uma subespécie dum gênero mais amplo: é o que acontece com a épica didática, entendida sempre [grifo meu] como uma subespécie da categoria mais ampla do epos." Em nota (67), Rossi refere um modo de diferenciação, entre a épica didática e a épica propriamente dita, com base apenas no estilo: comparada a esta, aquela corresponderia a um gênero leptón, o que explicaria a escolha, por parte dos alexandrinos calimaqueanos, de Hesíodo, e não Homero, como o seu modelo.

12. Não propriamente, ao menos em princípio, aquela de Arato de Solos

(III a.C.) e Nicandro

(c. II a.C.), ou mesmo Cícero (Arati Phaenomena).

13. Com base nalguns juízos de Tácito (Dial. 23) e Quintiliano (Inst. 1.4.4; 12.11.27), Clyde Murley (em "Lucretius, De Rerum Natura, Viewed as Epic". Transactions and Proceedings of the American Philological Association, Vol. 78 (1947), 336-46, 1944) procura mostrar que, já para os antigos, o poema de Lucrécio era visto não como poema didático, mas como épica, e que assim deve ser visto por nós. Alguns exageros a que chega talvez se expliquem pelo enquadramento demasiado parece adequado apenas, ao menos em princípio (ou "teoricamente"), à natureza do poema propriamente didático, vale dizer, à natureza do poema que tem por função precípua a instrução nalguma matéria e que se valha, para isso, do verso hexâmetro. Os Medicamina, porém, a exemplo das demais peças do ciclo didático erótico de Ovídio, também recorrem à paródia da poesia didática ${ }^{26}$, o que impossibilita, em princípio, a sua leitura como um poema de finalidade meramente didática (supondo-se, é claro, que tal tipo de poema pudesse existir). Poder-se-ia objetar, aqui, que os cem versos que nos restam dos Medicamina - sobretudo diante da natureza técnica de sua segunda parte (51-100) — não são bastantes para a determinação exata do alcance dessa paródia; entretanto, a descrição desse poema, por Ovídio, como pequeno (cf. Ars

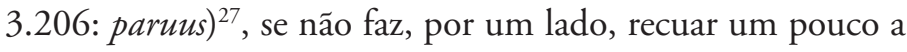
força de tal objeção, cria, por outro, a suspeita de que, já nesse detalhe mesmo - o da extensão do poema — resida um dos recursos da própria paródia, se considerada, nesse particular, a extensão média de cada livro das Geórgicas, por exemplo, e a extensão média dos poemas didáticos da tradição alexandri$n^{28}$; mas o que não é para ignorar, acima de tudo, é o fato de que justamente a principal palavra desse opúsculo sobre cosméticos - cultus -, que é a que define as direçôes do poema, seja, também ela, um objeto da paródia.

É em seu valor literal que Vergílio a emprega nas Geórgicas, quando diz, por exemplo, que a matéria cantada em seu poema foi o cultivo dos campos e o "cultivo", ou cuidado, do gado: Haec super aruorum cultu pecorumque canebam / et super arboribus ("Isso eu cantava sobre o cultivo dos campos e [o cuidado] do gado / e sobre as árvores", 4.569-60) ${ }^{29}$. Em seu sentido "geórgico", por assim dizer, também a emprega Ovídio quer no início daquele passo da Ars, já aludido (3.101-28), em que recomenda às mulheres o cuidado com a aparência: Cultis bene Liber ab unis / prouenit, et culto stat seges alta solo ("De cultivadas ["cuidadas"] videiras [é que] Líber [o "vinho"] abundantemente / provém, e em cultivado ["cuidado"] solo [é que] alta a seara se levanta", 3.101-2), quer no início dos Medicamina, em que louva os benefícios do cultivo: Cultus humum sterilem Cerealia pendere iussit I munera, mordaces interiere rubi. / Cultus et in pomis sucos emendat acerbos, / fissaque adoptiuas accipit arbor opes ("O cultivo mandou a terra estéril a Ceres pagar / pelas dádivas; as sarças cortantes extinguiram- 
se. / O cultivo, também, nos frutos corrige os acerbos sucos, / e, fendida, acolhe a árvore o auxílio dos enxertos”, 3-6). Ocorre, porém, que, tanto nesta quanto naquela passagem, Ovídio transita desse sentido "literal" de cultus para o sentido mais particular de "enfeite", "ornamento" (cf. Ars 3.103-20; Med. 7-10), uma vez que é esse, afinal, o objeto a ser tratado; mas o faz de modo a chamar a atenção para o momento mesmo em que um valor ainda não se distingue do outro: Ordior a cultu ("Começo pelo cultivo [o da terra $e$ o da beleza]), que é o início daquela passagem da Ars (3.101), e para o ponto mesmo de transição de um para outro valor: Culta placent ("As coisas cultivadas [ou "cuidadas", "enfeitadas"] agradam”, Med. 7). Isso parece ainda mais significativo diante da possibilidade especialmente num poeta como Ovídio - de um único elemento ser capaz de conotar, por sua presença mesma no sistema de significação em que está entrando (o "gênero" poético), todo o sistema de significação de que ele foi importado ${ }^{30}$. Se assim é, a polissemia de cultus, nessas passagens, aponta para duas direçôes: (1) o cultivo da terra, e portanto a alusão, nessa face, é à poesia didática propriamente, em particular à geórgica (por extensão, à grande "épica didática" vergiliana); e (2) o cultivo, ou o "cuidado", o "trato", da aparência (assim o do corpo como o de tudo o mais, como, por exemplo, as edificaçôes: cf. Med. 7-8; Ars 3.113-20), e portanto a alusão, nessa outra face, é à poesia elegíaca amorosa ${ }^{31}$. Nos Medicamina, particularmente, aquelas duas direções apontadas são de fato percorridas, se se considera, por um lado, que - dado o metro e as implicações da matéria (se não a matéria em si; cf. Med. 23-4) — ainda se trata, neles, duma extensão da elegia amorosa, e se se considera, por outro, que os requisitos do discurso didático se encontram, neles, preenchidos: a relação entre mestre e discípulo (cf. Med. 1: discite [...], puellae; 51: disce age; etc.); a instrução técnica distribuída e organizada em seções (cinco receitas de cosméticos: 53-66; 69-76; 77-82; 83-98; 99-100); painéis ilustrativos (11-6; 39-42); a ideia de utilidade da matéria ensinada (51-2; 67-8; 97-8); etc. ${ }^{32}$

O elemento didático entra, assim, na poesia elegíaca, mas, em vez de simplesmente se converter (ou traduzir-se) num elemento desta, reclama, já pela polissemia, os valores da própria poesia didática (especialmente a ideia de utilidade $\mathrm{da}$ instrução). $\mathrm{O}$ resultado, parece, não é apenas a atualização duma potencialidade interna ao discurso elegíaco amoroso ${ }^{33}$, teórico a que submete o $D e$ Rerum Natura: "O termo 'épico' [...] classifica o De Rerum Natura com muito mais efetividade. Aquele que nunca o tivesse lido, informado de que era tal, conheceria a relativa elevação do tema, o tom geral do tratamento, a extensão aproximada e o metro. Se informado unicamente de que era didático, ele não saberia nenhuma dessas coisas" ( $\mathrm{p}$. 346). É como dizer, pelo negativo, que o poema didático propriamente - o da tradição alexandrina, em suma — não tem matéria tão elevada quanto a da épica, nem é tão extenso. Se isso, por um lado, é mesmo verdade, parece incongruente, por outro, a afirmação de que não seria possível deduzir ou estimar o metro dum poema que nos dissessem ser didático, já que este, no mais das vezes, é o hexâmetro, como se sabe.

14. Cf.: Ne tamen omne meum credas opus esse remissum, / saepe dedi nostrae grandia uela rati. I Sex ego Fastorum scripsi totidemque libellos [...], "Não creias, porém, que toda a minha obra seja modesta [ou "relaxada", "dissoluta"], / dei amiúde grande vela ao meu barco. / Seis Fastos eu escrevi em mesmo número de livros [...]", Tr. 2.547-9.

15. Compare-se, p. ex., a argumentação de Ovídio, nos Tristia (2.219ss), segundo a qual Augusto, em meio a tantas ocupações, nunca teria tempo para ler a Ars Amatoria, com o testemunho de Donato (Verg. uita, 91-9), segundo o qual Vergílio, ajudado por Mecenas, teria lido 
para Augusto (já quando este regressava da batalha contra Antônio, em 29 a.C.), durante quatro dias seguidos, os quatro cantos de suas Geórgicas. Difícil é não pensar que os três livros da Ars somados ao dos Remedia, de certo modo sua continuação, façam eco ao número de livros do poema vergiliano.

16. Cf. Conte, p. 51-2, e LEACH, p. 149: "E. J. Kenney [sc. em "Nequitiae Poeta" in Ovidiana; Recheches sur Ovide publiées à l'occasion du bimillenaire de la naissance du poète, N. I. Herescu, ed., Paris, 1958, p. 201-9] observou como o vocabulário de Ovídio incorpora

palavras e expressões como quaere, nunc age, disce, adspicio, iubeo, que são importantes para criar o tom de instrução dum poema didático. A essas, podemos acrescentar as expressões tipicamente vergilianas labor e opus, que Ovídio usa para implicar a seriedade da tarefa do amante, e uia, que significa o curso da instrução e o caminho para o sucesso, em ambos os poemas [sc. na Ars Amatoria e nas

Geórgicas]. Vergílio amiúde aplica aos trabalhos dos agricultores o qualificativo durus, e Ovídio aplica esse adjetivo às puellae mesmas. Ambos os poetas dão ênfase frequentemente à necessidade de uota como uma parte de dedicação religiosa à tarefa. Ovídio [...] aborda sua matéria ligeira com um ar de cuidadosa gravidade". mas a transformação deste último - o que implica a sua ampliação - mediante o cruzamento dele com o didático. Essa "adaptação", contudo, não deve ser interpretada no espírito dum anódino cruzamento (Kreuzung), por si mesmo, entre gêneros, mas no espírito, digamos aqui, do "enxerto". O enxerto, diz Ovídio (cf. Med. 5-6), é um recurso do "cultivo" (cultus); ora, por um lado, o "cultivo" pode melhorar a poesia elegíaca, se fizer que dela nasçam frutos, isto é, se fizer que ela possa, tornando-se útil, responder de algum modo às necessidades contemporâneas - mais do que permanecer no velho impasse de negar os valores do mos maiorum sem nunca apresentar outros que lhes sirvam de substitutos ${ }^{34}$ - , mesmo que essas necessidades sejam as cosméticas, típicas do mundo refinado; daí, é a árvore da elegia que, fendida, acolhe o auxílio do enxerto (cf. Med. 6: fissa [...] adoptiuas accipit arbor opes), que é a poesia didática; o resultado é uma poesia elegíaca que ensina; por outro lado, pode ser a poesia didática a árvore que, fendida, acolhe em si mesma o auxílio da poesia elegíaca, uma vez que o "cultivo" também pode melhorar a poesia didática, se lhe corrigir um pouco do azedume (seja, em particular, o azedume da sua parte mais técnica, seja, em geral, o da matéria costumeiramente séria e de tom grandiloquente da poesia didática vergiliana; cf. Med. 5: cultus et in pomis sucos emendat acerbos, "o cultivo corrige nos frutos o acerbo suco"), quer conferindo a ela uma matéria nova e menor, relacionada a um tema urbano do universo erótico, quer vazando-a numa textura material nova, o dístico elegíaco, quer, enfim, subvertendo-lhe, ao menos em parte, o valor primeiro de utilidade e criando, por isso mesmo, a possibilidade de que seja lida com outro fim além daquele mesmo da instrução.

Que essa instrução é no mínimo possível é coisa assente. A julgar pelos resultados da pesquisa de Peter Green ${ }^{35}$, as receitas de cosméticos, na segunda parte dos Medicamina (51100), são de fato honestas quanto aos resultados prometidos, porque materialmente corretas, o que equivale a dizer que Ovídio, em suas lições, sabia mesmo do que estava falando, nada tendo inventado. Disso decorre, evidentemente, que os Medicamina talvez pudessem oferecer-se, dentro de certos limites, a um público interessado meramente na instrução, ainda que, para tais assuntos, pudesse haver autoridades específicas $^{36}$. Todavia, já nesse aspecto — o do público —, o poema de Ovídio parece jogar também com a ambiguidade, uma 
ambiguidade que, reverberando aquela da principal palavra do poema, age sobre aqueles limites e acarreta, pois, a indefinição deles, repercutindo diretamente sobre o modo de leitura do texto. Pois, em primeiro lugar, se o poema se endereça ao mesmo público (cf. 1: puellae; 43: puellae) a que se destina, em princípio, o terceiro livro da Ars Amatoria, como faz concluir aquele passo desta em que Ovídio alude aos seus Medicamina (cf. Ars 3.205: uestrae medicamina formae), então é possível admitir que esse público não fosse exatamente o das "moças pudicas" como sugeriria, à primeira vista, o uirginibus em Med. $32^{37}$-, mas o das mulheres do demi-monde romano, já presentes nos Amores; ocorre, porém, que o emprego de uestri mariti (cf. Med. 25) e nupta (cf. 26), se pode, por um lado, aludir a mulheres casadas incluídas nesse mesmo demi-monde (e sugestôes de que ele as incluía são encontráveis em Ovídio mesmo: cf. Am. 1.4; 3.4), não deixa, por outro lado, de acenar para a possibilidade de que os Medicamina também se endereçassem a mulheres casadas e a matronas não pertencentes a tal demi-monde ${ }^{38}$. Em segundo lugar, assim como o terceiro livro da Ars parece prever também — se não é garantido dizer "exclusivamente" 39 — um público masculino (para além duma mera interpelação retórica; cf. 5-6: Non erat armatis aequum concurrere nudas; / sic etiam uobis uincere turpe, uiri, "Não era justo contra [inimigos] armados [vós, mulheres] combaterdes desarmadas; / e também para vós, [ó] homens, vencer desse jeito [seria] torpe”), assim também poderiam prever os Medicamina, que revelariam aos homens, como na Ars, um aspecto a mais da arte feminina nas estratégias do amor. Essa indefinição com relação ao público moças e matronas versus mulheres do demi-monde; mulheres em geral versus homens - cria, como parte duma consciente estratégia de ambiguidade do poema, uma espécie de "inclusão ambígua" do leitor: dum lado, o valor, por assim dizer, sério (aquele da instrução) dos Medicamina atrairia, em princípio, o público (a) das mulheres do demi-monde, mas também, verossimilmente, o das moças e das matronas interessadas no cuidado da beleza, e, ainda que remotamente, o dos homens ${ }^{40}$; doutro lado, um outro valor, diferente do sério, visaria, em princípio, ao público (b) dos homens, mas também, verossimilmente, ao das mulheres cultas do demi-monde e, ainda que remotamente, ao das moças e matronas.

$\mathrm{O}$ primeiro de tais valores é da competência da poesia propriamente didática; quanto ao segundo, reconhecer a sua
17. Ainda assim, no caso dos Fastos, cumpre indagar se o uso do dístico não comprometeria deliberadamente a exposição de sua matéria elevada, de modo que o ritmo, nesse poema, fosse antes a maneira nova, para Ovídio, de interpretar a cultura e as tradições romanas, do que simplesmente uma escolha formal sem maior significado; cf. ToOHEY, p. 124-45.

18. Essa revisão do código elegíaco - na chave duma "ironia retrospectiva", como diz Conte (p. 55) —, é lícito dizer que começa já nos Amores, que iniciam, por assim dizer, uma progressiva "despersonalização" do amante elegíaco em proveito duma outra voz, a do preceptor didático (cf. Am. $1.4 ; 8)$, processo que se completaria, por sua vez, na Ars e nos Remedia. A fides do discurso didático garantiria, assim, o distanciamento necessário para o exercício dessa ironia e para a apresentação, enfim, de outras vozes, outros discursos, igualmente legítimos, para além daquele do amante sofredor, próprio da elegia.

19. O que complica o quadro é que esse problema parece conscientemente entregue pelo poeta ao seu leitor antigo, num circuito que, uma vez aberto por aquele, pode ser fechado por este em pelo menos duas maneiras: a escolha de uma delas não define apenas o texto, mas o próprio leitor; cf. GibSON, p. 25. 
20. O que não exclui, é fácil supor, uma forma oblíqua e ambígua de endereçamento, pois que também esse livro, a exemplo dos dois primeiros, pode endereçarse ao leitor masculino, que aí poderá instruir-se nas artimanhas de sua "presa".

Quanto a saber quem sejam essas "mulheres", particularmente no caso dos Medicamina, cf. infra.

21. Cf., a esse respeito, o artigo de Patricia Watson

("Ovid and Cultus: Ars Amatoria 3.113-28".

Transactions of the American Philological Association (1974-), Vol. 112, 237-44, 1982), que aponta, para $\mathrm{Am}$. 3.113-28, uma leitura mais estrita do conceito de cultus. Este não incluiria, ao menos nesse passo, o sentido mais amplo de sofisticação física e moral, mas conteria apenas uma referência, específica, à roupa feminina, seu penteado, etc.

22. Cf. Am. 1.8.26, 15.28; 2.4.37, 5.45, 10.5; 3.6.47, $6.55,7.1,9.66,15.15$.

23. Veja-se: Prisca imuent alios; ego me nunc denique natum / gratulor; haec aetas moribus apta meis, / [...] / [...] quia cultus adest, nec nostros mansit in annos / rusticitas priscis illa superstes auis ("O passado agrade a outros; eu, por ter nascido exatamente neste tempo, / dou graças; esta época é adequada ao meu caráter, / [...] / [...] porque aí está o ornato [cultus], e não se estende a nossos anos / aquela rusticidade [ou "desleixo"] que ainda sobreviveu aos nossos priscos avós"). Cf. ainda: $1.511 ; 3.23,101,433,681$. presença no poema, numa distinção em relação ao primeiro, passa pela necessidade da constatação, por parte do leitor antigo, de que a poesia que o encarna é de natureza híbrida. Esse leitor precisará ser capaz de jogar com o poeta no terreno mesmo da ambiguidade, porque, em primeiro lugar, o poeta joga com a possibilidade de seu poema ser lido realmente como um texto didático sério: ora, se o leitor reconhece apenas esse modo de leitura, parece que lê o texto pela metade, de modo imperfeito $^{41}$, tipo de leitura que caracterizaria, por sua vez, aquele primeiro público (a), que perderia, assim, o jogo, por não se aperceber de que se tratava de um jogo; mas, se, reconhecendo também um outro modo de leitura, o leitor ainda assim opta por ler o poema como apenas didático, é como se ainda perdesse o jogo, embora consciente, pelo menos, de que este existia. Em segundo lugar, o leitor há de saber jogar com o poeta porque, na circunstância mesma em que ele, leitor, tenha vislumbrado no poema um outro valor e o tenha admitido em sua relação com o valor didático, o poeta ainda joga, por um lado, com a competência do leitor — e agora o jogo, enfim, é de igual para igual entre este e aquele — na identificação do gênero poético do texto (considerada, aí, a importância que isso tinha para um leitor antigo), e, por outro lado, compartilha, com esse leitor, a compreensão desse mesmo valor não-didático imbricado no didático.

Ora, levando-se em conta a porção masculina desse público, tal valor não-didático poderia talvez identificar-se, não obstante, a um ensinamento bem particular: os Medicamina revelariam, ao menos em parte, aquilo que, segundo o código elegíaco ensinado na Ars (cf. 3.209-34), as mulheres jamais deveriam deixar que os homens observassem: Non tamen expositas mensa deprendat amator / pyxidas; ars faciem dissimulata iuuat ("Não vá, porém, o [teu] amante flagrar expostos sobre a mesa / os [teus] potes [de cosméticos]; a arte aproveita à aparência [apenas quando é] dissimulada", 3.209-10), pois, segundo esse código, o sucesso da arte (cf. 210: ars) do embelezamento é condicionado à sua ocultação ${ }^{42}$, já que aos homens causaria desagrado (cf. 211: offendat; 230: offendat) o conhecimento de detalhes do processo (cf. 211-6): Multa uiros nescire decet; pars maxima rerum / offendat, si non interiora tegas ("Muita coisa convém o homem não saber; a maior parte das coisas / desagradaria, se não escondêssemos o que lhe está por baixo", 229-30; cf. ainda: Multa [...], dum funt turpia, 
facta placent, "[...] muita coisa é torpe enquanto está sendo feita, [mas] agrada [quando já] feita”, 218). Essa revelação, por sua vez, talvez não fosse para causar "desagrado" junto aos leitores masculinos dos Medicamina. Talvez fosse, ainda por força do jogo, uma simples brincadeira, presente também no terceiro livro da Ars, que consistiria em dar aos homens a oportunidade de observarem de perto um dos aspectos da intimidade feminina que, em razão do código amoroso, lhes era interdito; essa observação, por sua vez, talvez lhes desse azo para o gracejo, para uma plaisanterie junto às mulheres, que, incluídas no público, poderiam, na medida de seu "cultivo", responder àquela brincadeira. Um movimento desse, que, quanto aos artifícios entre homens e mulheres, transita do mostrar para o esconder e do esconder para o mostrar, bem poderia definir aquela musa "jocosa" do poeta.

Já essa leitura dos Medicamina como um jogo — um jogo cuja principal exigência é de que não se leve o poema tão a sério —, parece confirmá-la o próprio Ovídio quando, cerca de nove anos após a publicação de sua Ars, faz a defesa dela no segundo livro dos Tristia. Como argumento para a sua causa, lista uma série de artes, ou poemas didáticos, cuja composição não resultou, como diz, em condenação para seus autores (cf. Tr. 2.492); mas essa lista, por sua vez, the vale como argumento na medida em que ele define aquela composição duma forma que diz respeito à sua Ars, pois, quanto a esta, chega a chamá-la de "tolo divertimento" (cf. 223: lusibus ineptis), produto de suas "horas vagas" (cf. 224: otia nostra) ${ }^{43}$, à qual, enfim, não se deve atribuir demasiada importância (cf. 277-8: Quicumque hoc concipit, errat, I et nimium scriptis adrogat ille meis, "Quem quer que pense isso [sc. que com a Ars corrompo as mulheres casadas], erra / e dá demasiada importância a meus escritos") ${ }^{44}$, e, quanto às artes da lista, começa já por dizer que algumas há, escritas por outros, "nas quais 'se brinca' com o jogo de dados" (cf. 471: Sunt aliis scriptae quibus alea luditur artes), concluindo, enumeradas as $\operatorname{artes}^{45}$, que "tais são coisas com as quais 'se brinca' no fumoso mês de dezembro" (cf. 491: Talia luduntur fumoso mense decembri) ${ }^{46}$. A "brincadeira" (ou o lusus), referida nesses passos, é o que subtrai a esses poemas o valor potencialmente nocivo que teriam, em princípio, se lidos seriamente, como teria, por exemplo, a Ars para as mulheres casadas, e, para a sociedade romana em geral, uma arte sobre um jogo proibido, como era
24. Compare-se essa visão com o seu oposto, em Vergílio, no final do segundo livro de suas Geórgicas (532-8; em particular, 532: Hanc olim ueteres uitam coluere Sabini, "Esta a vida que outrora cultivaram os velhos sabinos" e 538: aureus hanc uitam in terris Saturnus agebat, "esta a vida que na terra o áureo Saturno levava”); as sabinas de Ovídio aparecem como "sujas" (cf. Am.1.8.39: inmundae Sabinae), "rijas" (cf. 2.4.15: rigidas Sabinas), "carrancudas" (cf. 3.8.61: tetricas Sabinas).

25. Não há, ao menos no domínio da poesia préalexandrina, segundo M.L. West (Studies in Greek elegy and iambus. Berlin / New York: Walter de Gruyter, 1974, p. 18), precedentes para o uso do metro elegíaco na poesia didática de caráter técnico ou factual; do séc. III a.C., contudo, vem o nome de Filostéfano de Cirene (talvez discípulo de Calímaco), que escreveu em dísticos um poema sobre rios; cf. ToOHeY, p. 128.

26. Para o exame, em particular, da paródia dos poemas didáticos praticada pelos Medicamina, cf. especialmente WATSON, Patricia, "Parody and Subversion in Ovid's Medicamina Faciei Femineae". Mnemosyne, Fourth Series, Vol. 54, Fasc. 4 (Aug.), 457-71, 2001.

27. Com base na comparação entre a introdução dos Medicamina (1-50) e aquela dos livros da Ars Amatoria e dos Remedia, que varia entre 50 e 100 versos, a estimativa é de que o total dos 
Medicamina compreenderia aproximadamente 800 versos; cf. TooHey, p. 1612. Para outras observações acerca da extensão provável dos Medicamina, cf. Watson, "Parody and Subversion...”, p. 457.

28. Poemas, por exemplo, como o de Arato de Solos, os Phaenomena, de 1154 versos, e os de Nicandro, as Theriaca, de 958 versos, e os Alexipharmaca, de 630

versos.

29. Cf. ainda: 1.3.52, 102; 2.1.35, 51 .

30. Cf. Conte, p. 107-10; especialmente p. 108:

“Ovídio, por exemplo, é um poeta bastante interessado na possibilidade de usar certos elementos dentro de códigos diferentes. Ele é fascinado pelas coincidências e sobreposiçôes" (grifo meu).

31. Para outras observações acerca do conceito de cultus em Vergílio e Ovídio,

cf. Watson, "Parody and Subversion...", 461-2, 467-8.

32. Compare-se, ainda, p. ex., Ars 3.105: cura dabit faciem e Med. 1: quae faciem commendet cura a Verg. G. 1.3: quae cura bouum; e Med. 3-4: Cerealia pendere munera a Verg. G. 1.7:

Ceres, uestro si munere. Cf., em particular, Med. 45-6: [...] formam populabitur aetas, I et placitus rugis vultus aratus erit ("[...] a beleza, o tempo a devasta, / e o rosto uma vez belo será sulcado pelas rugas"). o de dados ${ }^{47}$. Uma das artes daquela lista, em particular, chama a atenção, e ainda mais se se considera que os Medicamina têm sua composição entre 2 e 1 a.C., isto é, aproximadamente entre a composição dos dois primeiros livros da Ars e a do terceiro $^{48}$ : trata-se da arte que trata do "cuidado com a pintura do rosto", isto é, a arte da "maquiagem": Composita est aliis fucandi cura coloris ("Outros compuseram sobre o cuidado com a maquiagem", Tr. 2.487). Quer, entre esses "outros", já esteja o próprio Ovídio, numa alusão a si mesmo e ao próprio poe$\mathrm{ma}^{49}$, quer se trate, aí, apenas duma alusão genérica a outros poetas (em meio aos quais, talvez, estivesse um modelo seu), o fato é que se faz referência, nesse ponto, à arte cosmética. Nessas condições, é correto deduzir que uma arte como essa, a exemplo das demais da lista, também pudesse ser lida como uma "brincadeira" poética; mas também é lícito supor, a partir daí, que os Medicamina, como uma arte cosmética, também pudessem ser assim entendidos.

Pode ser que a única implicação séria do jogo, nesse opúsculo de Ovídio, seja a lição sobre a arte e seus enganos. Uma lição cujo fim é mostrar os "bastidores", ou o que está por dentro (cf. Ars 3.330: interiora), da beleza, e contribuir, desse modo, para descortinar a ficção do teatro elegíaco, desfazendo-a: os ingredientes dos cosméticos e seu modo de preparo, para quem na pequenez do dístico esperasse, ainda, a elegia amorosa primeira de Ovídio, talvez soassem rispidamente, como se lembrassem, já pelo aspecto mais concreto da matéria, que o mundo é maior do que o resumo dele feito pela elegia romana. Um mundo grande assim, entrando no pequeno discurso elegíaco, só poderia causar seu alargamento e, no limite, sua posterior dissolução. Os Medicamina, ao que parece, estão ao meio do caminho entre uma e outra coisa.

\section{Ovídio, Produtos para a Beleza Feminina: TRAduÇÃo pó́tica}

Sabei como cuidar, ó moças, da aparência, e como conservar vossa beleza.

Cuidada, a terra antes infértil paga a Ceres os dons, de sarças livra-se cortantes,

5. e, se há cuidado, o acerbo suco a fruta emenda, fendida acolhe a árvore os enxertos. 
O que é cuidado apraz. O ouro os tetos cobre, o mármore reveste a negra terra, retintas são as lãs no caldeirão de Tiro,

10. marfim provê a Índia ao fino corte.

As sabinas de Tácio mais talvez quisessem, que a si, as terras cultivar dos pais, quando a matrona, rubicunda no alto assento, fiava, firme o dedo, a longa peça,

15. e recolhia o gado, ela mesma, que a filha pastara, e a lenha ao fogo inda deitava. Mas vossas mães geraram moças delicadas: quereis douradas roupas ter no corpo, quereis mudar o corte às comas odorosas,

20. notável pelas joias ter a mão; vossos colares são de pedras do Oriente, tamanhas que à orelha duas pesam. Mas não desdoura: que cuideis de aparecer, que os homens hoje em dia já se exibem.

25. Como a mulher vossos maridos se embelezam e mais enfeites têm que a própria esposa. Todas se aprontam para si, pouco importando que amores cacem: não há crime nisso.

Bem que as oculte o campo, o Atos escarpado,

30. lá mesmo se penteiam, bem cuidadas.

É também deleitoso agradar-se a si mesma: as moças têm prazer de serem belas.

Se alguém as louva, a ave de Juno as suas plumas mostra, toda orgulhosa da beleza.

35. O amor assim mais se conquista que por ervas que experta mão de bruxa horrenda sega. Em matos não creiais, ou mistas beberagens, nem no nocivo humor de égua no cio; encantos marsos não dividem as serpentes,

40. à fonte não reflui o curso d'água; que bem alguém golpeie os bronzes temeseus, não cairá a Lua de seu carro.

Antes cuidai de vossos modos, ó garotas: à beleza o caráter aproveita,

45. o amor ele assegura; o corpo o tempo assola, e a bela face as rugas sulcarão.
33. Nem simplesmente a "declinação do paradigma elegíaco no gênero feminino", como Conte aponta no caso das Heroides; cf. Conte, p. 121-2; Ov. Am. 2.18.19-34.

34. Como resposta àquela contradição, nos elegíacos anteriores, que viria a ameaçar, com uma tensão, a própria estrutura da elegia romana, a saber, a inclusão, ainda que por transcodificação, de elementos da tradição num sistema poético que procurava ser a alternativa a essa tradição; cf. CONTE, p. 39-40.

35. Green, Peter, "Ars Gratia Cultus: Ovid as Beautician”. The American Journal of Philology, Vol. 100, № 3 (Autumn), 381-92, 1979. Green procura deduzir, a partir duma detalhada comparação com outras fontes (Plínio, sobretudo), quais efeitos se acreditava que tais cosméticos tinham, e estimar, com o auxílio do conhecimento químico e dermatológico moderno, quais efeitos esses cosméticos realmente têm. A conclusão é de que tais ingredientes estão de fato relacionados com a limpeza da pele e a remoção de manchas do corpo: "Por que um mero jeu d'esprit literário praticaria uma tal discriminação cosmética? E - um corolário que nos deveria dar o que pensar - se os Medicamina objetivavam ser uma recomendação prática séria, não é possível que nós tenhamos, semelhantemente, subestimado o propósito prático da Arte de Amar?" (p. 392). 
36. Como observa Patricia Watson ("Parody and Subversion...”, p. 468), Ovídio provavelmente obteve suas receitas a partir de algum tratado técnico de cosmética, do tipo daqueles mencionados mais tarde (II d.C.) por Galeno (De compositione medicamentorum secundum locos 12.401.5, 403.16, 416.5, 432.13, etc.).

37. Esse verso (cf.: uirginibus cordi grataque forma est, "às moças [ou às "jovens mulheres"] interessa e agrada a sua própria beleza”) seria comparável ao segundo, quase idêntico, deste dístico da Ars: Delectant etiam castas praeconia formae; I uirginibus curae grataque forma sua est, "Deleitam também as castas os elogios à sua beleza; / às moças [ou às "jovens mulheres"] importa e agrada a sua própria beleza”, 1.621-2), no qual uirginibus de fato se refere a moças castas, não sendo este, contudo, o público da Ars Amatoria em geral. Ainda assim, dado o uso que Ovídio faz da palavra uirgo noutros momentos - como, p. ex., em Am. 2.1.5 - seria possível supor que seu uso nos Medicamina não devesse implicar necessariamente "moças pudicas"; cf. NiKOlaidis,

Anastasios G., "On a Supposed Contradiction in Ovid (Medicamina Faciei 18-22 vs. Ars Amatoria 3.129-32)". The American Journal of Philology, Vol. 115, No 1 (Spring), 97103, 1994, p. 98.
Tempo haverá de vos dar pena olhar o espelho, outra razão de rugas essa pena.

A virtude é bastante e dura longo tempo,

50. e, enquanto dura, dela o amor depende.

Vê como, o sono assim que deixa o tenro corpo, pode raiar nas faces a brancura.

Pega a cevada que por mar os líbios mandam, tira-lhe toda a palha e mais a casca.

55. Tanto igual de ervilhaca ovos dez umedeçam, tendo a cevada nua duas libras.

A isso tudo assim que o vento houver secado, em mó rugosa lenta a burra moa.

$\mathrm{E}$ os chifres que primeiro ao vivo cervo caem,

60. tritura e duas onças aproveita.

Assim que essa mistura uma farinha forme, de pronto passa tudo na peneira.

Póe de narciso doze bolbos sem a casca, que firme, em limpo mármore, a mão pile,

65. duas onças de goma e trigo da Toscana, o nônuplo de mel aí se junte.

Um tal produto a que aplicar em suas faces mais lisa brilhará que seu espelho.

Nem duvides torrar os pálidos tremoços,

70. da fava junto assando os grãos inflados;

seis libras pesem uns e outros igualmente, a uns e outros passa em negras mós.

Nem te falte a cerusa ou do rubente nitro a espuma, e a íris que na Ilíria nasce.

75. Que braços jovens tudo amassem por igual: moído, pese tudo uma só onça.

$\mathrm{O}$ produto dos ninhos queixosos as manchas da face tira: chamam-no alcioneu.

O quanto dele, se perguntas, me contenta:

80. é só cortar a onça em duas partes.

Pra que dê liga e pelo corpo bem se esfregue, o flavo mel da Ática acrescenta.

Inda que o incenso aplaque os deuses quando irados, não há só de acender em seus altares.

85. O incenso ao nitro junta alisador da pele, pondo de cada um da libra um terço. 
Três quartos põe de goma, à casca retirada, e um cubinho de mirra resinosa.

Tritura tudo e passa então por fino crivo,

90. pela adição de mel contendo o pó.

É bom juntar o funcho à perfumosa mirra, cinco escrópulos dum e nove doutra,

de ressequida rosa o quanto a mão apanhe,

e, com o sal de Amão, o incenso macho.

95. Despeja nisso tudo o creme da cevada, incenso e sal pesando como as rosas.

Por pouco tempo que se aplique à tenra face, terá uma bela cor o rosto inteiro.

Vi uma que a papoula em água fria punha

100. e, amassada, aplicava nas bochechas.

\section{Medicamina Faciei Femineae}

(Texto latino: J.H. Mozley; G.P. Goold, 1979.)

Discite quae faciem commendet cura, puellae,

Et quo sit uobis forma tuenda modo.

Cultus humum sterilem Cerealia pendere iussit

Munera, mordaces interiere rubi.

5. Cultus et in pomis sucos emendat acerbos,

Fissaque adoptiuas accipit arbor opes.

Culta placent. Auro sublimia tecta linuntur,

Nigra sub imposito marmore terra latet:

Vellera saepe eadem Tyrio medicantur aëno:

10. Sectile deliciis India praebet ebur.

Forsitan antiquae Tatio sub rege Sabinae

Maluerint, quam se, rura paterna coli:

Cum matrona, premens altum rubicunda sedile,

Assiduum duro pollice nebat opus,

15. Ipsaque claudebat quos filia pauerat agnos,

Ipsa dabat uirgas caesaque ligna foco.

At uestrae matres teneras peperere puellas.

Vultis inaurata corpora ueste tegi,

Vultis odoratos positu uariare capillos,

20. Conspicuam gemmis uultis habere manum:

Induitis collo lapides oriente petitos,

Et quantos onus est aure tulisse duos.
38. Daí, talvez, o laesae, em Ars 3.207, significasse algo como "danificada [pelo tempo(?)]": cf.: hinc quoque praesidium laesae petitote figurae, "nele [sc. no poema dos $M e d$.] também podereis buscar o socorro para a aparência [que se encontra] danificada”, em consonância com Med. 2: [discite] quo sit uobis forma tuenda modo, "[aprendei] de que modo a beleza há de ser por vós conservada"; cf. ainda: NIKOLAIDIS, p. 100:

"As matronas romanas, na medida em que pudessem tirar proveito das receitas de Ovídio [...], podiam estar incluídas nele [sc. no público dos Medicamina], mas não ao ponto da exclusão dos destinatários naturais [grifo meu], as moças do demimonde romano".

39. Cf., porém, ToOHey, p. 164; LEACH, p. 149.

40. Os versos 24-5 dos Medicamina (cf.: cum comptos habeant saecula nostra uiros. / Femineae uestri poliuntur lege mariti, "pois nossos tempos trazem os homens enfeitados. / Vossos maridos alisam a cútis conforme o uso feminino"), ainda que se limitem à condição de argumento para o que precede (cf.: sit uobis cura placendi, "haja em vós [sc. mulheres / moças] a preocupação de parecer belas", 23), não deixam de ser sugestivos.

41. Como também seria se fizesse o inverso: no caso, p. ex., de ler um poema épico ou épicodidático com a mente (a "significação" ou a própria moralidade do leitor; $\mathrm{cf}$. Gibson, p. 25) incorreta 
(cf. Tr. 2.275-6: [...] carmen, recta si mente legatur, I constabit nulli posse nocere meum, "[...] que meu poema, se for lido com juizo correto, / a ninguém pode lesar, será coisa assente”), nele atentando apenas para o caráter erótico: cf. Tr. 2.257-62: Quodcumque attigerit, siqua est studiosa sinistri, I ad uitium mores instruet inde suos. / Sumpserit Annales - nibil est hirsutius illis —, I facta sit unde parens Ilia, nempe leget; / sumpserit 'Aeneadum genetrix' ubi prima, requiret, I Aeneadum genetrix unde sit alma Venus

("Toque [sc. a matrona] o [poema] que for, se é propensa ao que é errado, / a partir dele instruirá no vício o seu caráter. / Tome os Anais [de Ênio] — nada é mais áspero que eles -, I como Ília se tornou mãe é o que neles decerto vai ler;

/ tome o [poema começado por] 'a mãe dos enéadas' [= De Rerum Natura ], perguntará / como alma Vênus é [= tornou-se] mãe dos enéadas").

42. Como é também o sucesso masculino na arte da conquista: cf. Ars

2.313-4: Si latet ars, prodest; adfert deprensa pudorem I atque adimit merito tempus in omne fidem ("Se não aparece, a arte é útil; [se é] descoberta, causa vergonha / e com razão arrebata para sempre a confiança”).

43. Cf. ainda: 238: nostros iocos; 307: uersus molles; 331: numeris leuioribus; 332: paruos modos; 339: leue opus, iunenalia carmina; 349: delicias et mollia carmina.
Nec tamen indignum: sit uobis cura placendi, Cum comptos habeant saecula nostra uiros.

25. Feminea uestri poliuntur lege mariti, Et uix ad cultus nupta, quod addat, habet. Se sibi quaeque parant, nec quos uenentur amores Refert; munditia crimina nulla merent.

Rure latent finguntque comas; licet arduus illas

30. Celet Athos, cultas altus habebit Athos.

Est etiam placuisse sibi cuicumque uoluptas;

Virginibus cordi grataque forma sua est.

Laudatas homini uolucris Iunonia pennas

Explicat, et forma multa superbit auis.

35. Sic potius iungendus amor quam fortibus herbis, Quas maga terribili subsecat arte manus.

Nec uos graminibus nec mixto credite suco,

Nec temptate nocens uirus amantis equae;

$\mathrm{Nec}$ mediae Marsis finduntur cantibus angues,

40. Nec redit in fontes unda supina suos;

Et quamuis aliquis Temesaea remouerit aera, Numquam Luna suis excutietur equis.

Prima sit in uobis morum tutela, puellae.

Ingenio facies conciliante placet.

45. Certus amor morum est: formam populabitur aetas,

Et placitus rugis uultus aratus erit.

Tempus erit, quo uos speculum uidisse pigebit,

Et ueniet rugis altera causa dolor.

Sufficit et longum probitas perdurat in aeuum,

50. Perque suos annos hinc bene pendet amor.

Disce age, cum teneros somnus dimiserit artus,

Candida quo possint ora nitere modo.

Hordea, quae Libyci ratibus misere coloni,

Exue de palea tegminibusque suis.

55. Par erui mensura decem madefiat ab ouis:

Sed cumulent libras hordea nuda duas.

Haec ubi uentosas fuerint siccata per auras,

Lenta iube scabra frangat asella mola:

Et quae prima cadent uiuaci cornua ceruo,

60. Contere in haec (solidi sexta fac assis eat).

Iamque ubi puluereae fuerint confusa farinae,

Protinus in cumeris omnia cerne cauis. 
Adice narcissi bis sex sine cortice bulbos,

Strenua quos puro marmore dextra terat.

65. Sextantemque trahat gummi cum semine Tusco:

Huc nouies tanto plus tibi mellis eat.

Quaecumque afficiet tali medicamine uultum

Fulgebit speculo leuior ipsa suo.

Nec tu pallentes dubita torrere lupinos,

70. Et simul inflantes corpora frige fabas;

Vtraque sex habeant aequo discrimine libras,

Vtraque da nigris comminuenda molis.

Nec cerussa tibi nec nitri spuma rubentis

Desit et Illyrica quae uenit iris humo.

75. Da ualidis iuuenum pariter subigenda lacertis:

Sed iustum tritis uncia pondus erit.

Addita de querulo uolucrum medicamina nido

Ore fugant maculas: alcyonea uocant.

Pondere, si quaeris, quo sim contentus in illis,

80. Quod trahit in partes uncia secta duas.

Vt coeant apteque lini per corpora possint,

Adice de flauis Attica mella fauis.

Quamuis tura deos irataque numina placent,

Non tamen accensis omnia danda focis.

85. Tus ubi miscueris radenti tubera nitro,

Ponderibus iustis fac sit utrimque triens.

Parte minus quarta dereptum cortice gummi,

Et modicum e myrrhis pinguibus adde cubum.

Haec ubi contrieris, per densa foramina cerne:

90. Puluis ab infuso melle premendus erit.

Profuit et marathros bene olentibus addere myrrhis,

(Quinque trahant marathri scrupula, myrrha nouem)

Arentisque rosae quantum manus una prehendat,

Cumque Ammoniaco mascula tura sale.

95. Hordea quem faciunt, illis affunde cremorem:

Aequent expensas cum sale tura rosas.

Tempore sint paruo molli licet illita uultu,

Haerebit toto multus in ore color.

Vidi quae gelida madefacta papauera lympha

100. Contereret, teneris illineretque genis.

Recebido em fevereiro de 2013

Aprovado em abril de 2013
44. Cf. ainda: 219-24:

Scilicet imperii princeps statione relicta / imparibus legeres carmina facta modis?

/ Non [...] / in [...] tuis

umeris tam leve fertur onus,

/ lusibus ut possis advertere

numen ineptis, / excutiasque oculis otia nostra tuis

("Sem dúvida, tu, chefe do império, abandonando o

teu posto, / lerias poemas

compostos em versos

desiguais?... / Não [...] /

[...] vai sobre os teus

ombros peso assim tão leve,

/ que a tolos divertimentos

possas voltar a tua

majestade / e examines com teus próprios olhos o fruto de minhas horas vagas”).

45. Artes que versam sobre: o jogo com "ossinhos"

(473); uma espécie de jogo de tabuleiro (477);

o jogo de bola (485); a

arte de nadar (486); uma

brincadeira infantil com um

aro metálico (486); a arte

de pintar o rosto (487); as

regras para o banquete e a

recepção (488); a fabricação

de copos (489) e de vasilhas

para vinho (490).

46. Se a referência ao mês de dezembro é, por extensão,

às Saturnais, então o mês

em que tais poemas são

praticados (luduntur) é

precisamente o mês do

divertimento e da liberdade.

47. Jogo que, embora proibido, era do gosto de

Augusto, como reporta

Suetônio (Aug. 71).

48. Cf. Rosati, G., Ovidio: I Cosmetici delle Donne. Venezia, Marsilio, 1985, introd.

49. Como sustenta J.

Gómez Pallarès, em seu

"Sobre Ovídio, Tristia II,

471-492”, Latomus 52

(1993), 380-1. 
